\title{
Height and weight pattern up to 20 years after treatment for acute lymphoblastic leukaemia
}

\author{
N H Birkebæk, N Clausen
}

\begin{abstract}
Objective-To assess height and body mass index standard deviation scores up to 20 years after treatment for acute lymphoblastic leukaemia (ALL). Subjects and methods-Height and body mass index standard deviation scores were measured in 33 patients (14 boys and 19 girls) with childhood ALL at diagnosis, after the end of treatment, at final height, and at follow up 10-20 years (median, 16.2) after diagnosis. Eleven patients were treated with chemotherapy only and 22 patients were treated with chemotherapy and cranial irradiation.

Results-In the chemotherapy only group, height standard deviation scores were the same at follow up as at diagnosis, but there was a significant decrease in height standard deviation scores during treatment. Mean body mass index standard deviation scores increased steadily from the start of treatment until final height and continued to increase from final height until follow up. In the cranially irradiated group, mean height standard deviation scores decreased steadily from the start of treatment until follow up. Mean body mass index standard deviation scores increased continuously from the start of treatment until final height and from final height until follow up.
\end{abstract}

Conclusion-Chemotherapy combined with cranial irradiation and chemotherapy alone might be persisting risk factors for obesity even after final height has been attained in patients treated for childhood ALL. Chemotherapy is a risk factor for reduced final height only when administered in combination with cranial irradiation. These problems need to be recognised and dealt with at follow up examination. (Arch Dis Child 1998;79:161-164)

Keywords: acute lymphoblastic leukaemia; body mass index standard deviation score; height standard deviation score; chemotherapy; radiotherapy

Department of Pediatrics, University Hospital of Aarhus at Skejby, 8200 Aarhus N, Denmark

N H Birkebæk

$\mathrm{N}$ Clausen

Correspondence to: Dr N H Birkebæk,

Skovgårdsparken 44, 7080 Børkop, Denmark.

Accepted 11 March 1998 ever, the children were followed for only four to eight years in two of these studies. ${ }^{45}$ Chemotherapy alone resulted in a slightly reduced final height in one study, ${ }^{7}$ and in normal final height in another study. ${ }^{8}$ The effect of treatment for ALL on weight has not been investigated extensively ${ }^{9-14}$ and in only two reports were the patients followed up to their 18 th year or until the end of growth. ${ }^{11}{ }^{12}$ In addition, in these studies, all patients had received cranial irradiation. Weight changes after final height has been attained have not been examined in this group of patients.

Our study examined height and weight changes in patients followed for 10 to 20 years after treatment for childhood ALL, with and without cranial irradiation.

\section{Patients and methods}

Of 37 survivors in first remission who had attained final height after a diagnosis of childhood ALL in our institution from 1973-84, 33 individuals (14 boys and 19 girls) were investigated. Two patients had left our department 10 years ago, one patient was excluded because of Asiatic origin, and one patient had height and weight measured only at diagnosis. Eleven patients had received chemotherapy only (C), while 22 patients had received both chemotherapy and cranial irradiation, 24 Gy in 15 fractions $(C+I)$. All patients had received a standard ALL treatment consisting of vincristine and prednisone in a five week induction phase. This was followed by consolidation with 10 daily injections of L-asparaginase in all nonirradiated children and nine irradiated children. Patients with an increased risk of relapse received three doses of doxorubicin in the induction phase. This comprised 18 of the 22 irradiated patients and five of the 11 nonirradiated patients. The latter five patients also received reinduction treatment with one injection of vincristine and a one week course of prednisone every one to two months. Only three irradiated children received reinduction treatment. Maintenance treatment with oral mercaptopurine daily and methotrexate once a week was given to all patients for a total of two and a half years. Central nervous system leukaemia prophylaxis consisted of three courses of intermediate dose methotrexate with $500 \mathrm{mg} / \mathrm{m}^{2}$ in those patients who did not receive irradiation. All patients were given intrathecal methotrexate.

After finishing treatment, patients were seen in the outpatient clinic every one to two years until the age of at least 25 years. Data for height and weight at the time of diagnosis, after the end of treatment, at final height, and at follow up were registered from the charts. Age for final height was defined as the age at which the change in height was less than $1 \mathrm{~cm} /$ year of observation. Patients having a body mass index 
standard deviation score greater than 1.28 (above the 90th percentile) were considered obese. ${ }^{10}$

STATISTICAL METHODS

Height data were analysed as height standard deviation score (HSDS). HSDS $=(\mathrm{h}-<\mathrm{h}>) /$ $\mathrm{SD}$, where $\mathrm{h}$ is the measured height, and $<\mathrm{h}>$ and SD are the mean height and standard deviation for height, respectively, for the patient's age and sex in a reference population of Swedish children followed from birth to final height. ${ }^{15}$ Weight data were analysed as body mass index (BMI) standard deviation score (BMISDS). BMISDS $=(\mathrm{BMI}-<\mathrm{BMI}>) / \mathrm{SD}$, where $\mathrm{BMI}$ is the measured weight/squared height, and <BMI $>$ and SD are the mean BMI and standard deviation, respectively, for the patient's age and sex in a French reference population between 0 and 87 years of age. ${ }^{16}$ The Student's $t$ test was used for statistical evaluation.

\section{Results}

The median age at diagnosis was 4.3 years (range, 1.2-13.3), the median age at the end of treatment was 7.25 years (range, 3.3-16.6), the median age at final height was 16.4 years (range, 15.0-18.3), and the median age at follow up examination was 20.5 years (15.0 27.0). The median period of follow up after start of treatment was 16.2 years (range, 10.820.7).

The mean body mass index standard deviation scores increased significantly from diagnosis until final height in both groups (table 1). The largest increase in mean body mass index standard deviation scores was found during treatment. At follow up, mean body mass index standard deviation scores had increased further

Table 1 Mean body mass index standard deviation scores (BMISDS) and mean differences ( $\triangle B M I S D S)$ at various time points for the chemotherapy group and the chemotherapy and cranial irradiated group

\begin{tabular}{|c|c|c|c|c|}
\hline & \multicolumn{2}{|c|}{$\begin{array}{l}\text { Chemotherapy } \\
(n=11)\end{array}$} & \multicolumn{2}{|c|}{$\begin{array}{l}\text { Chemotherapy plus irradiation } \\
(n=22)\end{array}$} \\
\hline & $\begin{array}{l}\text { Mean } \\
\text { BMISDS }\end{array}$ & $\begin{array}{l}\triangle B M I S D S \\
(S E M)\end{array}$ & $\begin{array}{l}\text { Mean } \\
\text { BMISDS }\end{array}$ & $\begin{array}{l}\triangle B M I S D S \\
(S E M)\end{array}$ \\
\hline At diagnosis & -0.60 & & -0.50 & \\
\hline At end of therapy & 0.22 & & 0.16 & \\
\hline At final height & 0.60 & & 0.61 & \\
\hline At follow up & 1.02 & & 1.39 & \\
\hline End of therapy - diagnosis & & $0.83(0.26) \dagger$ & & $0.66(0.19) \dagger$ \\
\hline Final height - end of therapy & & $0.36(0.41)$ & & $0.46(0.24)$ \\
\hline Final height - diagnosis & & $1.19(0.38) \dagger$ & & $1.09(0.29) \dagger$ \\
\hline Follow up - final height & & $0.43(0.22)^{\star}$ & & $0.78(0.18) \dagger$ \\
\hline
\end{tabular}

Table 2 Mean height standard deviation scores (HSDS) mean differences in scores ( $\triangle H S D S$ ) at various time points for the chemotherapy group and the cranial irradiation and chemotherapy group

\begin{tabular}{|c|c|c|c|c|}
\hline & \multicolumn{2}{|c|}{$\begin{array}{l}\text { Chemotherapy } \\
(n=11)\end{array}$} & \multicolumn{2}{|c|}{$\begin{array}{l}\text { Chemotherapy plus irradiation } \\
(n=22)\end{array}$} \\
\hline & $\begin{array}{l}\text { Mean } \\
\text { HSDS }\end{array}$ & $\begin{array}{l}\triangle H S D S \\
(S E M)\end{array}$ & $\begin{array}{l}\text { Mean } \\
\text { HSDS }\end{array}$ & $\begin{array}{l}\triangle H S D S \\
(S E M)\end{array}$ \\
\hline At diagnosis & 0.86 & & 0.65 & \\
\hline At end of therapy & 0.00 & & -0.19 & \\
\hline At follow up & 0.74 & & -0.58 & \\
\hline End of therapy - diagnosis & & $-0.86(0.16)^{\star}$ & & $-0.83(0.15)^{\star}$ \\
\hline Follow up - diagnosis & & $-0.13(0.18)$ & & $-1.27(0.12)^{\star}$ \\
\hline
\end{tabular}

${ }^{\star} \mathrm{p}<0.001$ in both the $\mathrm{C}+$ I group $(\mathrm{p}<0.01)$ and in the $\mathrm{C}$ group $(p=0.08)$ compared with body mass index standard deviation scores at final height. In both the $\mathrm{C}+\mathrm{I}$ and the $\mathrm{C}$ group, $36 \%$ of the patients were obese at follow up.

At diagnosis, the mean height standard deviation scores in both groups were higher than the average of the normal population. Mean height standard deviation scores were significantly reduced during treatment in both groups (table 2). At follow up, the mean height standard deviation score was reduced further in the $\mathrm{C}+\mathrm{I}$ group compared with the height standard deviation score at the end of treatment, while in the $\mathrm{C}$ group, the mean height standard deviation score had increased to the value seen at diagnosis.

\section{Discussion}

Weight reference curves for the age group 20-30 years do not exist. Because many patients in our study were in this age group, we used body mass index standard deviation scores as an index of obesity. ${ }^{10}$ Body mass index standard deviation scores increased from diagnosis during treatment, and until final height in both groups. Even after final height had been attained, body mass index standard deviation scores continued to increase in both treatment groups. To our knowledge, this is the first report on weight changes in childhood ALL patients after final height has been attained. In addition, long term follow up weight data on patients with childhood ALL treated with chemotherapy alone have not been published previously. In general, our children were tall and slender at the time of diagnosis and of normal weight after cessation of treatment. However, many were overweight at final height, and even more obese at a median follow up time of 16.2 years after start of treatment, when $36 \%$ of our patients in both treatment groups were obese. There have been only two long term studies on the weight changes up to final height in patients with childhood ALL. In both studies, all patients had received cranial irradiation. In one study, Schell found that $38 \%$ of patients were overweight at the age of $18 .{ }^{11}$ In the other study, Didi found that $45 \%$ of girls and $47 \%$ of boys were obese at final height, using body mass index standard deviation scores $>85$ th percentile as the definition of obesity. ${ }^{12}$

Van Dongen-Melman demonstrated, by comparing body mass index standard deviation scores up to four years after treatment for ALL in six treatment protocols, that ALL protocols with the highest glucocorticoid dose induced the highest weight gain. ${ }^{10}$ Our observation of a weight gain in the treatment period, regardless of whether cranial irradiation had been given, indicates that chemotherapy might be a major factor in the aetiology of weight gain during treatment. Of the drugs used, glucocorticosteroid is the only one with a known effect on weight gain, and this drug might be responsible for the increased weight during treatment, in accordance with the proposal of van DongenMelman. However, common factors such as restriction of activity level and focusing on diets 
rich in calories might contribute to the weight gain during treatment, and these factors might establish habits that continue after treatment.

In our population, body mass index standard deviation scores increased further during the follow up period, independently of treatment modality. Thus, cranial irradiation is not of major importance for the weight gain in this period. Glucocorticoid treatment does not seem to contribute to obesity at follow up because only two of our eight patients who had received the highest corticosteroid load during reinduction with corticosteroids were obese. All patients were given intrathecal methotrexate. One could speculate that in some sensitive patients this treatment might affect the "satiety centre" in the hypothalamus. Deficiency of growth hormone might cause changes in the body composition towards adiposity. ${ }^{17}$ However, we did not find any correlation between growth hormone deficiency and obesity; but we found a strong correlation between serum leptin concentrations and obesity, the significance of which is unclear. ${ }^{18}$ Future studies of obesity in ALL patients should include pharmacological, biochemical, genetic, and psychological factors.

Our population of children with ALL was significantly taller at the time of diagnosis compared with the normal population. This has been seen in other cohorts of children with ALL, ${ }^{319}$ although other studies have demonstrated height standard deviation scores of zero at diagnosis. ${ }^{80}$ Whether the coexistence of ALL and a high growth rate is incidental or the result of a common factor is not known. At the end of treatment, the height standard deviation scores had fallen significantly to the level of the normal population in both treatment groups, indicating that cranial irradiation was not responsible for height growth reduction during the treatment period. A similar growth suppression has been demonstrated previously during treatment for ALL with and without cranial irradiation..$^{58}$ This could be a result of treatment with compounds such as cortisone and methotrexate, ${ }^{21}$ the disease itself, and/or complications of the treatment. In accordance with other studies, ${ }^{2} 36722$ we showed a further reduction in height standard deviation scores from the end of treatment to final height in the $\mathrm{C}+\mathrm{I}$ group. There are few studies concerning height standard deviation scores at final height in patients with ALL who have been treated with chemotherapy alone. Our findings of final height standard deviation scores at the same value as at diagnosis confirmed the results of Holm, ${ }^{8}$ although Sklar found a reduction of height standard deviation scores at final height in a group of patients treated with chemotherapy alone. ${ }^{7}$ However, Sklar used a more intensive chemotherapy regimen, including a four drug maintenance treatment with vincristine, prednisone, mercaptopurine, and methotrexate, which might explain the reduction in final height in his study.

In conclusion, both chemotherapy alone and in combination with cranial irradiation leads to a weight gain during treatment for ALL. The weight gain often continues in both treatment groups after the end of treatment. Even after

\section{Key messages}

- Chemotherapy and chemotherapy combined with cranial irradiation increase mean body mass index standard deviation scores from diagnosis to final height in patients treated for childhood acute lymphoblastic leukaemia

- For both treatments, a further increase in body mass index standard deviation scores occurs after final height has been attained

- Chemotherapy and chemotherapy combined with cranial irradiation reduce height standard deviation scores during treatment

- Chemotherapy alone does not reduce final height in patients treated for childhood acute lymphoblastic leukaemia

final height has been attained, many patients have a further weight gain. Chemotherapy in ALL causes a reduction in height gain during treatment, but this height reduction persists only when chemotherapy is combined with cranial irradiation. Height and weight problems are common after treatment for ALL. They must be detected and dealt with at follow up, as both a short stature and obesity might cause great long term problems.

The authors thank The National Research Council of Health Sciences (Svend Terp, Master of Economy), for statistical advice.

1 Ching-Hon P. Childhood leukemias. $N$ Engl $f \mathrm{Med}$ 1995;332:1618-29.

2 Dacou-Voutetakis C, Kitra V, Grafakos S, Polychronopoulou S, Drakopoulou M, Haidas S. Auxologic data and hormonal profile in long-term survivors of childhood acute lymphoid leukemia. Am f Pediatr 1993;15:277-83.

3 Uruena M, Stanhope R, Chessells JM, Leiper AD. Impaired pubertal growth in acute lymphoblastic leukaemia. Arch pubertal growth in acute lym

4 Kirk JA, Stevens MM, Menser MA, et al. Growth failure and growth-hormone deficiency after acute lymphoblastic leukaemia. Lancet 1987;i:190-3.

5 Clayton PE, Morris-Jones PH, Shalet SM, Price DA. Growth in children treated for acute lymphoblastic leukaemia. Lancet 1988;i:460-2.

6 Schriock EA, Schell MJ, Carter M, Hustu O, Ochs JJ. Abnormal growth pattern and adult short stature in 115 long-term survivors of childhood leukemia. $\mathcal{F}$ Clin Oncol 1991;9:400-5.

7 Sklar C, Mertens A, Walter A, et al. Final height after treatment for childhood acute lymphoblastic leukemia: comparison of no cranial irradiation with 1800 and 2400 centiprays of cranial irradiation. 7 Pediatr 1993;123:59-64

8 Holm K, Nysom K, Hertz H, Muller J. Normal final height after treatment for acute lymphoblastic leukemia without irradiation. Acta Pcediatr 1994;83:1287-90.

9 Sainsbury CPQ, Newcombe RG, Hughes IA. Weight gain and height velocity during prolonged first remission from acute lymphoblastic leukaemia. Arch Dis Child 1985;60: 832-6.

10 Van Dongen-Melman JEWM, Hokken-Koelega ACS, Hahlen K, De Groot A, Tromp CG, Egeler RM. Obesity after successful treatment of acute lymphoblastic leukemia in childhood. Pediatr Res 1995;38:86-90

11 Schell M, Ochs JJ, Schriock EA, Carter M. A method of predicting adult height and obesity in long-term survivors of childhood acute lymphoblastic leukemia. f Clin Oncol 1992;10:128-33.

12 Didi M, Didcock E, Davies HA, Ogilvy-Stuart AL, Wales $\mathrm{JKH}$, Shalet SM. High incidence of obesity in young adults after treatment of acute lymphoblastic leukemia in childhood. F Pediatr 1995;127:63-7.

13 Zee P, Chen CH. Prevalence of obesity in children after therapy for acute lymphoblastic leukemia. Am $\mathcal{F}$ Ped Hematol Oncol 1986;8:294-9.

14 Odame I, Reilly JJ, Bibson BE, Donaldson MD. Patterns of obesity in boys and girls after treatment for acute lymphobobesity in boys and girls after treatment for acute
lastic leukaemia. Arch Dis Child 1994;71:147-9.

15 Karlberg P, Taranger J, Engstrøm, et al. Physical growth from birth to 16 years and longitudinal outcome of the 
study during the same age period. Acta Paediatr 1976; 258(suppl):7-76.

16 Rolland-Cachera MF, Cole TJ, Sempe M, Tichet J, Rossignol C, Charraud A. Body mass index variations: centiles from birth to 87 years. Eur F Clin Nutr 1991;45:13-21.

17 Armbrust W, Tamminga RYJ, Kamps WA. Body composition after treatment for acute lymphoblastic leukemia (ALL). Med Pediatr Oncol 1994;23:274

18 Birkebæk NH, Fisker S, Clausen N, Tuovinen V, SindetPedersen S, Christiansen JS. Growth and endocrinological disorders up to 21 years after treatment for acute lymphoblastic leukemia in childhood. Med Pediatr Oncol 1998;30 $351-6$.
19 Broomhall J, May R, Lilleyman JS, Milner RDG. Height and lymphoblastic leukaemia. Arch Dis Child 1983;58:300-1.

0 Robison LL, Nesbit ME, Sather HN, Meadows AT, Ortega JA, Hammond GD. Height of children successfully treated for acute lymphoblastic leukemia: a report from the late effects study committee of childrens cancer study group. Med Pediatr Oncol 1985;13:14-21.

21 Moell C, Garwicz S. High-dose methotrexate causes shortterm suppression of growth in rabbits. Acta Paediatr 1995; 84:1237-40.

22 Moell C, Marky I, Hovi L, et al. Cerebral irradiation causes blunted pubertal growth in girls treated for acute leukemia. Med Pediatr Oncol 1994;22:375-9.

\section{Acute haemorrhagic oedema of childhood}

Would you recognise acute haemorrhagic oedema of childhood (AHO) if you saw it? The condition is said to have been described first by Snow in 1913 and, although there have been only around 90 cases reported since then, it may be more common than that might imply because it may often be mistaken for Henoch-Schönlein purpura (HSP) (L A Gonggryp and colleagues, Pediatric Dermatology 1998;15:91-6).

The condition affects children between the ages of 4 months and 2 years and is characterised by ecchymotic purpura on the face (ears, eyelids, cheeks) and limbs, the lesions often having a target-like or cockade appearance and accompanied by local oedema. (Cockade; a ribbon, knot of ribbons, rosette, etc, worn in the hat as a badge of office or party, or as part of a livery dress-Shorter Oxford English Dictionary.) The lesions illustrated seem to be about 2 or $3 \mathrm{~cm}$ in diameter and are circular, with an outline consisting of two dark red parallel lines (tramline effect) surrounding fairly normal looking skin. Other lesions look like bruises or haemorrhagic papules. Some are tender. The child usually seems well although some have a mild fever. The condition almost always resolves within a week or two but may recur, although when it does recur it usually does so early. There has been debate about whether it is a variant form of HSP but it seems milder, without the gastrointestinal, joint, or kidney involvement of HSP, and with a totally benign course. Histologically the skin lesions of AHO and HSP are similar. Two of four children in this report, from South Africa, had tuberculosis. Previously reported associations have been with vaccination, respiratory infection, drugs, streptococci, staphylococci, and adenoviruses.

Is there any point in distinguishing between AHO and HSP? The skin lesions are different, the age range of AHO is more restricted, extracutaneous involvement is rare, and it is entirely benign. So probably there is. 